FINAL SCIENTIFIC REPORT OF EERE DE-EE0000576 PROJECT

\title{
A NOVEL LOW THERMAL BUDGET THIN-FILM POLYSILICON FABRICATION PROCESS FOR LARGE-AREA, HIGH-THROUGHPUT SOLAR CELL PRODUCTION
}

\author{
Yue Kuo \\ Thin Film Nano \& Microelectronics Research Laboratory \\ Texas A\&M University, College Station, TX 77843-3122
}

\begin{abstract}
A novel thin-film poly-Si fabrication process has been demonstrated. This low thermal budget process transforms the single- and multi-layer amorphous silicon thin films into a poly-Si structure in one simple step over a pulsed rapid thermal annealing process with the enhancement of an ultrathin Ni layer. The complete poly-Si solar cell was fabricated in a short period of time without deteriorating the underneath glass substrate. The unique vertical crystallization process including the mechanism is discussed. Influences of the dopant type and process parameters on crystal structure will be revealed. The poly-Si film structure has been proved using TEM, XRD, Raman, and XPS methods. The poly-Si solar cell structure and the performance have been examined. In principle, the new process is potentially applicable to produce large-area thin-film poly-Si solar cells at a high throughput and low cost. A critical issue in this process is to prevent the excessive dopant diffusion during crystallization. Process parameters and the cell structure have to be optimized to achieve the production goal.
\end{abstract}

\section{INTRODUCTION}

\section{Requirement of a Large-Area, Low-cost Thin Film Poly-Si Solar Cell Fabrication Process for Industry}

The worldwide annual energy consumption is predicted to grow from the current 13 terawatt-years (TWyr) to as much as 30 TWyr by 2050. Along with other renewable energy sources, e.g., wind, hydro, biomass, and geothermal, solar energy is one of the most important green energies. The solar cell market grows at an annual rate of $25 \%-30 \%$ and the learning curve yields a factor of two drop in cost every 8-10 years, which makes it an attractive market. In general, the solid-state solar cell has the advantage of a long life with steady operation efficiency. The energy required for producing the system does not exceed $10 \%$ of the total energy generated by the system during its anticipated operational lifetime for single crystalline or multicrystalline Si. The energy payback time for crystalline Si (sc-, poly-, or mc-Si) is less than 3 years. In spite of the lower conversion efficiencies of the Si-based solar cells compared with the compound semiconductor solar cells, they are the dominate mass production technology, i.e., $>90 \%$. The conversion efficiency decreases in the order of $\mathrm{sc}-\mathrm{Si}>$ poly-Si $>\mu \mathrm{c}-\mathrm{Si}>\mathrm{a}-\mathrm{Si}[1]$. 
Although solar cells with the highest conversion efficiencies are made of bulk materials, the thinfilm approach is promising because it provides many advantages, such as small amount of composing materials with almost unlimited supplies at low costs, low-energy fabrication processes, and large-area substrate capability. According to van Sark et al. [2], the total thin-film solar cell market share will quickly grow to $25 \%$ in 2010 . In spite of its relatively low conversion efficiencies, the thin-film a-Si solar cell is expected to occupy about $60 \%$ of the solar cell market by 2010 [2]. The main reason is its low manufacturing cost. For example, the thin-film a-Si solar cell can be fabricated using the low temperature, e.g., $200^{\circ} \mathrm{C}$, PECVD process on large-area glass substrates with a high throughput. PECVD has been widely used in the thin-film transistor liquid crystal display (TFT LCD) industry with the capability of handling large-size glass substrates, e.g., $3 \mathrm{~m} \mathrm{x}$ $3 \mathrm{~m}$. Recently, the $\mu \mathrm{c}-\mathrm{Si}: \mathrm{H}$ solar cell received a great deal of attention recently as a replacement for a-Si as the thin-film solar cell production technology because of its high conversion efficiency. However, the PECVD $\mu \mathrm{c}-\mathrm{Si}$ deposition process requires a high hydrogen concentration and a large power density.

The thin-film poly-Si solar cell is promising for commercial applications for its high conversion efficiency and stability. However, the biggest challenge in thin-film poly-Si solar cell fabrication is how to form the intrinsic and doped poly-Si thin films at high rates under the low thermal budget condition so that the large-size, low-cost substrate, such as glass, can be used. Conventionally, the direct poly-Si deposition process, e.g., LPCVD, requires a temperature of $>650^{\circ} \mathrm{C}$, which is too high for the low-cost glass [3]. The grain size and quality increase with the increase of temperature. The laser recrystallization method is improper for large-area substrate production although it provides high quality poly-Si. The solid phase crystallization (SPC) method can transform a-Si into poly-Si at a low temperature, e.g., $550^{\circ} \mathrm{C}$. However, it requires a long time, e.g., $>20$ hours. The SPC time can be shortened by using the metal-induced crystallization method, e.g., with $\mathrm{Al}, \mathrm{Ni}, \mathrm{Pd}$, ITO, or $\mathrm{Cr}$. The crystallization time can reduce to half, e.g., $10 \mathrm{hrs}$ at $550^{\circ} \mathrm{C}$, which is still too long for mass production. Therefore, the technology bottleneck of the thin-film poly-Si solar cell is its high process temperature. Once this problem is solved, it can be mass produced on the glass substrate at the low cost.

\section{A new poly-Si thin film formation process - pulsed rapid thermal annealing (PRTA) enhanced with the vertically metal-induced crystallization (VMIC) mechanism}

Previously, Kuo reported a novel PRTA process that was used to crystallize a Ni-contacted a-Si thin film into a poly-Si thin film on a Corning 7059 glass [4]. It is based on the principle of exposing a substrate to short heating-cooling cycles repeatedly, as shown in Figure 1. The heating time in each cycle can be short and the cooling time can be long. It was reported that the SPC time decreases with the increase of the temperature, i.e., following linear $\log (t)-(1 / T)$ relationship [5]. For example, the crystallization time can be reduced by 5 orders of magnitude if the temperature is increased from $560^{\circ} \mathrm{C}$ to $800^{\circ} \mathrm{C}$ [5]. The crystallization time can be further reduced when a proper metal is in contact with the a-Si layer, i.e., the MIC process [3]. Using the PRTA Ni MIC method, a thin a-Si film was successfully transformed into a poly-Si film [4]. The poly-Si film structure is similar to that of the 36-hour $500^{\circ} \mathrm{C}$ SPC poly-Si film. The glass substrate remains flat without warping or cracking [6]. PRTA is a very low thermal budget process that heats the surface thin film to a high temperature for a very short period of time, e.g., $<1 \mathrm{sec}$ as shown in Figures 1(a) and (b). The glass substrate 
temperature remains below it softening temperature. The commercial large-area RTA system for TFT fabrication is available [7].

(a)

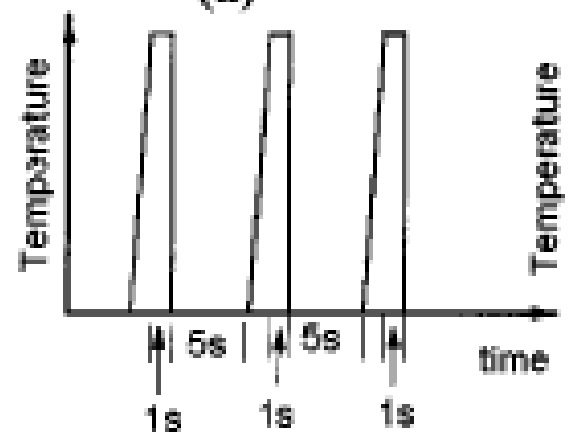

(b)

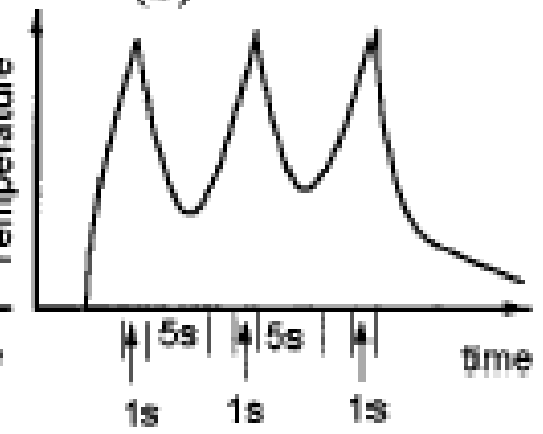

Figure 1 (a) Programmed and (b) actual PRTA temper-ature profiles [4].

\section{EXPERIMENTAL}

The 100nm molybdenum (Mo) and $\sim 1 \mathrm{~nm}$ nickel (Ni) thin films were sputter deposited on a dilute HF cleaned Corning 1737 glass in one pumpdown. Then individual $\mathrm{n}^{+}, \mathrm{i}$, and $\mathrm{p}^{+}$layers were deposited by PECVD using $\mathrm{SiH}_{4} / \mathrm{PH}_{3} / \mathrm{H}_{2}, \mathrm{SiH}_{4}$, and $\mathrm{SiH}_{4} / \mathrm{B}_{2} \mathrm{H}_{6} / \mathrm{H}_{2}$ gases, separately, at $250^{\circ} \mathrm{C}$ and $750 \mathrm{mTorr}$. For the Figure 2 stack preparation, the $\mathrm{n} / \mathrm{i} / \mathrm{p} / \mathrm{SiN}_{\mathrm{x}}$ 4-layer was deposited sequentially in the same chamber without breakdown the vacuum. The top $\operatorname{SiN}_{\mathrm{x}}$ layer was used to prevent air contamination.

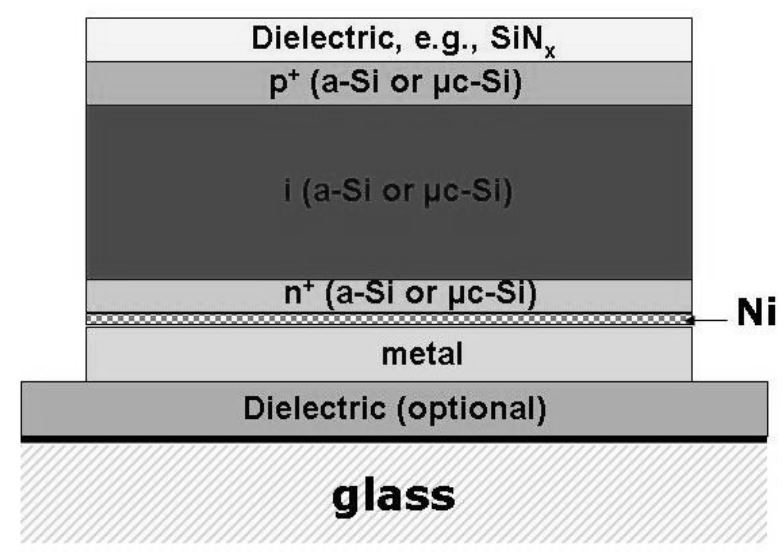

Figure 2 As-deposited a-Si $\mathbf{n}^{+} / \mathbf{i} / \mathbf{p}^{+} / \mathrm{SiN}_{\mathrm{x}}$ on $\mathrm{Mo} / \mathrm{Ni}$ electrode.

The nip stack was exposed to a PRTA process to form the poly-Si structure. For example, Figure 3 shows the programmed and actual temperatures of a 10-pulse PRTA process. Each cycle is composed of $1 \mathrm{sec}$. of heating at $850^{\circ} \mathrm{C}$ and $5 \mathrm{sec}$. of cooling (by turning the heating lamp off). The actual temperature after each cooling cycle increases with the increase of the number of pulses, which is adjustable according to the heating and cooling times. 


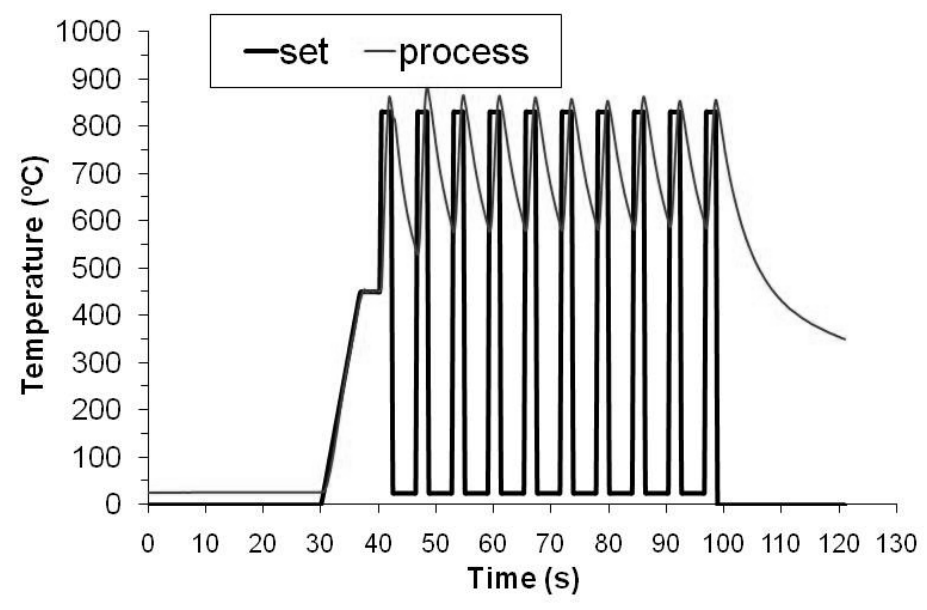

Figure 3 Programmed and actual temperature profiles of a 10-pulse PRTA process.

\section{RESULTS AND DISCUSSIONS}

\section{Crystallization of individual layers}

Figure 4 shows the XRD pattern of a $900 \mathrm{~nm}$ thick intrinsic PECVD a-Si layer after being dehydrogenated at $500^{\circ} \mathrm{C}$ followed by a 10 -pulse $1 \mathrm{~s} 850^{\circ} \mathrm{C}-5 \mathrm{~s}$ cooling PRTA process. The original amorphous film was transformed into the polycrystalline film with main orientations of (111) and (220). A minor (311) peak is also detected. The grain size is between $200 \AA$ and $300 \AA$.

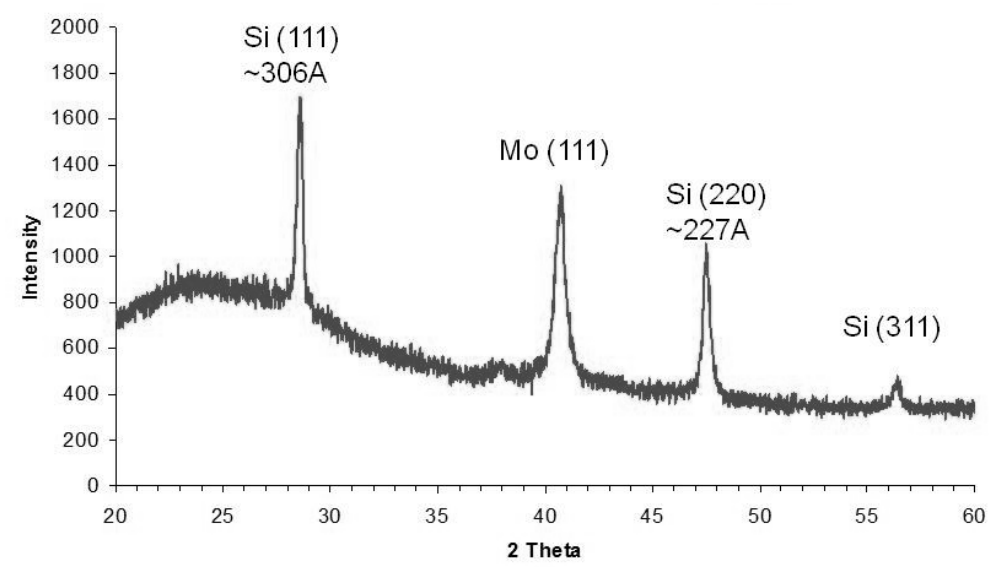

Figure 4 XRD of a PECVD intrinsic a-Si film after dehy-drogenation and a 10-pulse PRTA process (1s 850 $\mathrm{C}-5 \mathrm{~s}$ cooling ).

The PRTA crystallization is also applicable to doped a-Si films. For example, Figure 5 shows the TEM picture of a phosphorus-doped $\mathrm{n}^{+}$PECVD a-Si film after dehy-drogenation and a 10-pulse $1 \mathrm{~s}$ $850^{\circ} \mathrm{C}-5$ s cooling PRTA process. The poly-Si structure is clearly observable. The film's conductivity 
is improved by 2 orders of magnitude after the crystallization process due to the improvement of the doping efficiency.

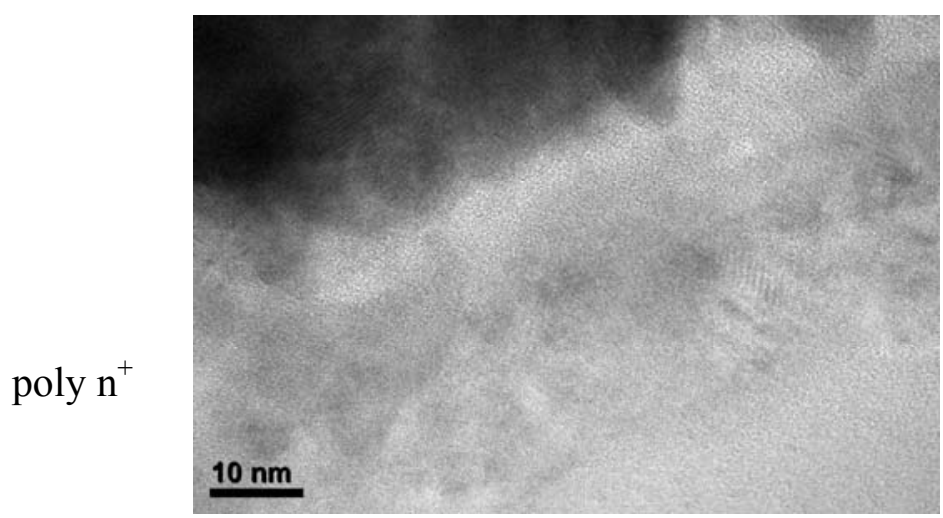

Figure 5 TEM of a PECVD ${ }^{+}{ }^{+}$a-Si film after dehydro-genation and a 10-pulse PRTA process (1s 850 $0^{\circ} \mathrm{C}-5$ s cooling).

Figure 6 shows the boron-doped $\mathrm{p}^{+}$poly-Si film formed from PRTA of a PECVD $\mathrm{p}^{+}$a-Si film. The poly-Si film's conductivity is also much higher than that of the original $\mathrm{p}^{+}$film. Therefore, the crystallization phenomenon is independent of the dopant type.

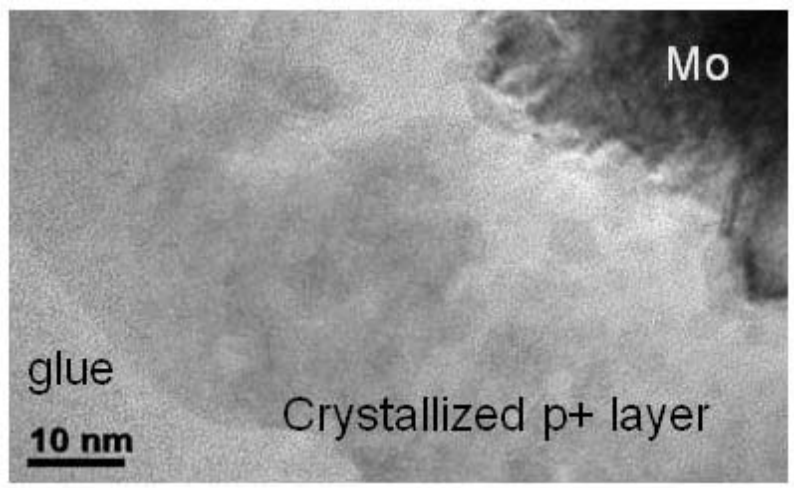

Figure 6 TEM of a PECVD $\mathrm{p}^{+}$a-Si film after dehydro-genation and a 10-pulse PRTA process (1s 850 ${ }^{\circ} \mathrm{C}-5$ s cooling).

The $1 \mathrm{~nm}$ thick Ni layer is critical to this a-Si crystallization phenomenon. Separately, an intrinsic or doped PECVD a-Si was directly deposited on the Mo surface without the $1 \mathrm{~nm}$ thick Ni layer. Under the same 10-pulse $1 \mathrm{~s} 850^{\circ} \mathrm{C}$ heating-5s cooling PRTA process condition, the film remained amorphous.

Both Figures 5 and 6 shows an amorphous interface layer between the Mo and the poly-Si layers. This interface is probably formed from the out diffusion of oxygen from the bulk the Mo film or the native oxide at the original Mo surface since the Mo/Ni layer was exposed to air before the PECVD a-Si layer deposition. Separately, oxygen in the original film was removed with various methods, 
e.g., plasma hydrogenation, HF dip, or minimum air exposure of the Mo/Ni film, before PECVD aSi film deposition. In all cases, the crystallization phenomenon is detected after PRTA. Therefore, oxygen in the original Mo layer does not interfere or facilitate the transformation of the a-Si film into the poly-Si film.

Separately, we have carried out experiments to eliminate the possibility of crystallization of the a-Si film during the low-temperature dehydrogenated process by measuring the XRD pattern and the TEM picture of the film before PRTA. No poly-Si structure was observed without the PRTA step. It takes a long period of time, e.g., 20 hours, to crystallize the a-Si film using the Ni-induced process under a low temperature, e.g., $500^{\circ} \mathrm{C}$, condition [6]. The dehydrogenation time in this experimental was too short, e.g., $1 \mathrm{hr}$, to cause the crystallization of the film.

\section{Crystallization of the complete pin stack}

The complete $\mathrm{n}^{+}(20 \mathrm{~nm}$ to $50 \mathrm{~nm}) / \mathrm{i}(250 \mathrm{~nm}$ to $1 \mu \mathrm{m}) / \mathrm{p}^{+}(20 \mathrm{~nm}$ to $50 \mathrm{~nm})$ stack was deposited by PECVD on a Mo/Ni coated glass substrate under one pumpdown condition. After PRTA, it was transformed into a poly-Si stack. Figure 7 shows the electron diffraction patterns of the stack (a) before and (b) after PRTA. Separately, each composition layer in the nip stack was crystallized from TEM pictures.

(a)

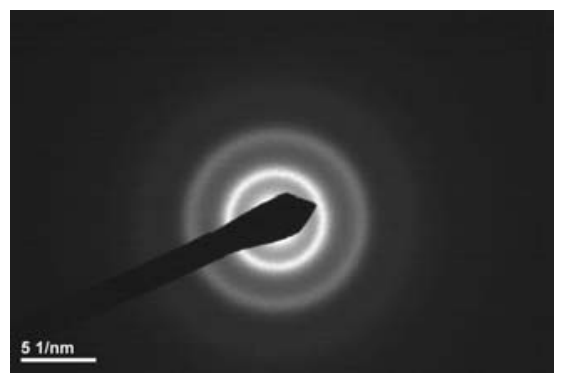

(b)

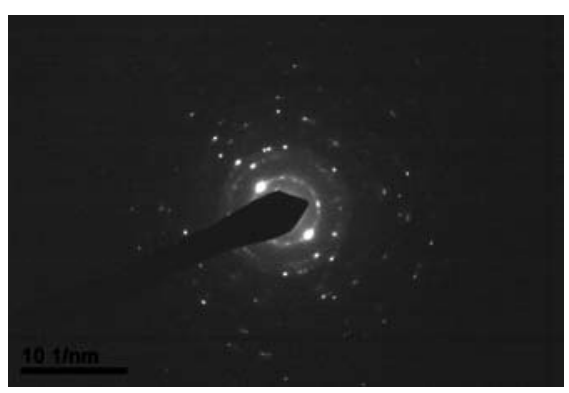

Figure 7 Electron diffraction patterns of a PECVD a-Si nip stack (a) before and (b) after a 10pulse PRTA process.

The crystallization phenomenon is further proved by Raman spectra. For example, Figure 8 shows Raman spectra of (a) the as-deposited a-Si p $(30 \mathrm{~nm}) / \mathrm{i}(2 \mu) / \mathrm{n}(30 \mathrm{~nm})$ stack and (b) the PRTA treated poly-Si pin stack. The $250^{\circ} \mathrm{C}$ PECVD a-Si stack was deposited on a Mo $(100 \mathrm{~nm}) / \mathrm{Ni}(1 \mathrm{~nm})$ coated Corning 1737 glass. Before PRTA, the a-Si stack was dehydrogenated at $500^{\circ} \mathrm{C}$ for up to 10 hours and the Raman spectrum shows amorphous phase only. After PRTA, it shows the poly-Si 
phase. Twp peaks located at $518.5 \mathrm{~cm}^{-1}$ and $512.2 \mathrm{~cm}^{-1}$ correspond to the crystalline phase. The small shoulder peak at $480 \mathrm{~cm}^{-1}$ indicates the existence of the amorphous phase. The volume fraction of the crystalline phase is estimated to be about 70\%. Separately, a-Si pin stacks were treated with different number of pulses. The result shows that although the original amorphous film was crystallized after only a few pulses, the volume fraction of the crystalline phase changes slightly with the number of pulses. This result is compliment to the TEM and XRD results obtained previously that the a-Si pin stack was definitely transformed into poly-Si stack.

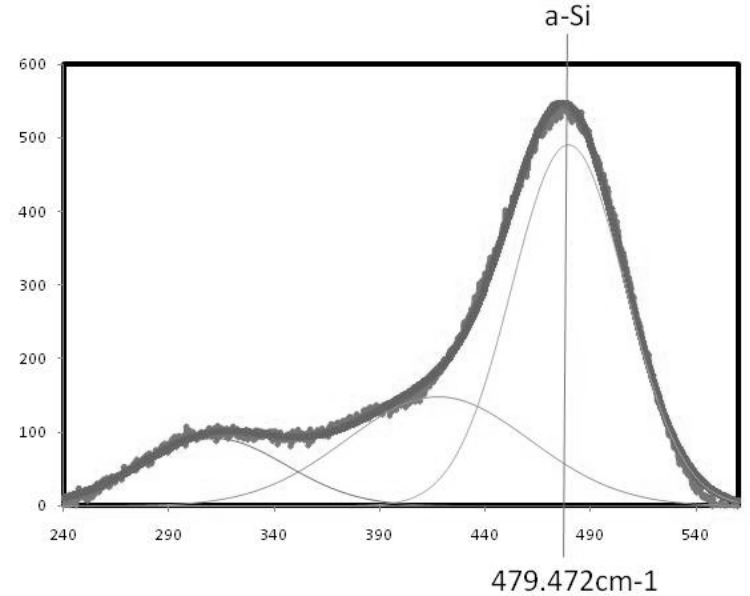

(a)

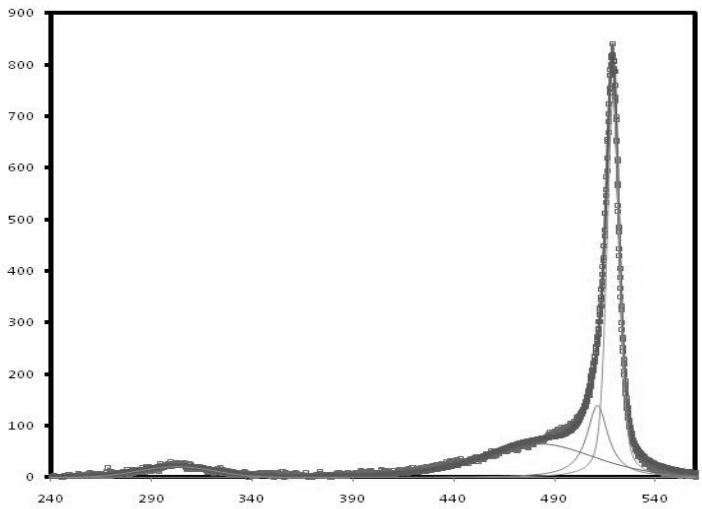

(b)

Fig. 8. PECVD a-Si pin stack (a) before and (b) after 10 pulses of $1 \mathrm{~s} 850^{\circ} \mathrm{C} / 5 \mathrm{~s}$ cooling.

\section{Mechanism of vertical crystallization of a-Si stack}

The mechanism of the vertical crystallization of the a-Si nip stack through the PRTA process can be explained by Figures 9(a) and (b). Upon the sudden increase of temperature at the initial PRTA stage, the $1 \mathrm{~nm}$ thick Ni layer forms a nanometer-thick $\mathrm{NiSi}_{2}$ layer at the $\mathrm{Ni}-\mathrm{n}^{+}$interface. Since the $\mathrm{Ni}$ layer was very thin, only the $\mathrm{NiSi}_{2}$ was formed. With the increase of the number of heat pulses, the $\mathrm{NiSi}_{2}$ layer is moved from the $\mathrm{n}^{+}$layer to the intrinsic layer, as shown in Fig. 9(a). Due to the small lattice mismatch between $\mathrm{NiSi}_{2}$ and $\mathrm{Si}$, the passage of the former causes the alignment of $\mathrm{Si}$ atoms, i.e., crystallization, in the $\mathrm{n}^{+}$, intrinsic, and $\mathrm{p}^{+}$layers. Eventually, the complete nip stack is crystallized, as shown in Fig. 9(b). This mechanism is applicable whether the original PECVD film is amorphous or microcrystalline. 
(a)

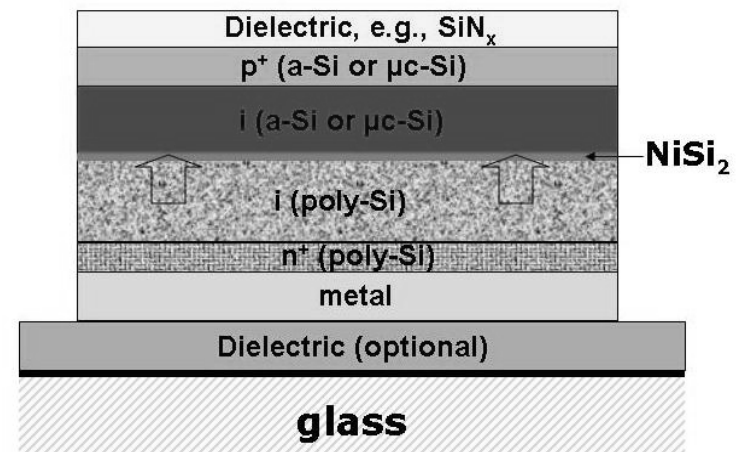

(b)

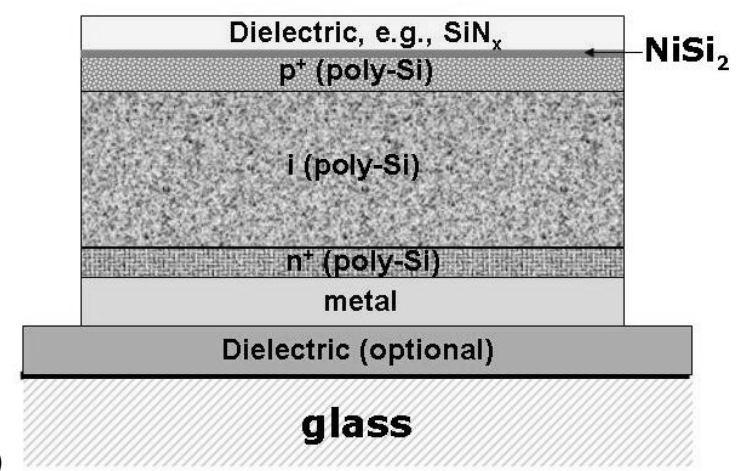

Figure 9 (a) $\mathrm{NiSi}_{2}$ formation at the early stage and (b) after propagation through the complete nip stack.

The Ni-enhanced crystallization process can be further proved using the XPS analysis method. For example, Figure 10 shows the XPS spectra of the Ni 2p peak on the (a) a-Si nip and (b) PRTA crystallized poly-Si nip surfaces, which are above the Mo/Ni electrode surface by about $310 \mathrm{~nm}$ thickness. No Ni peak was detected on the a-Si nip surface because of the lack of diffusion during the a-Si nip stack deposition, e.g., $250^{\circ} \mathrm{C}$. However, after PRTA, the Ni $2 \mathrm{p}$ peak is clearly detected. The Ni peak can be decomposed into $\mathrm{NiSi}_{\mathrm{x}}$ and Ni peaks, which further confirms the $\mathrm{NiSi}_{2}$ diffusion enhanced Si crystallization mechanism.

Ni2p

(b)

(a)

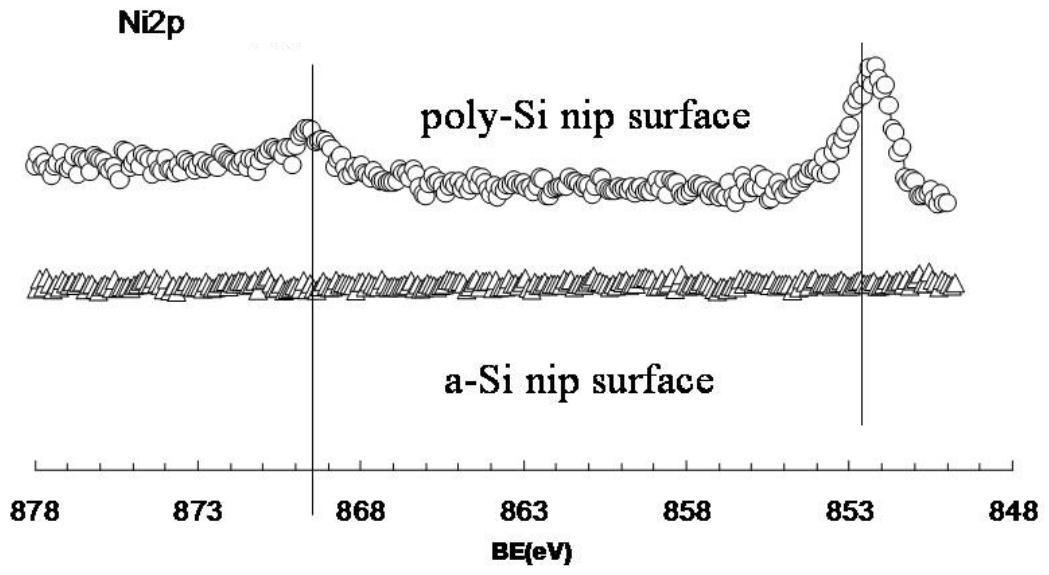

Fig. 10. XPS Ni 2p of (a) a-Si and (b) PRTA poly-Si nip surfaces. 
In summary, the TEM picture showed that the sputter deposited $1 \mathrm{~nm} \mathrm{Ni}$ film was not continuous, i.e., in the discrete nano dot form. Crystals were formed locally from the Ni-Si contact region. Strictly speaking, the $\mathrm{NiSi}_{2}$ layer is not propagated uniformly from the bottom to the top. However, since the transport rate is high at the high temperature, macroscopically, the crystallization process can be taken as uniform. In addition, separately, it was observed that Ni was diffused from the Mo surface of the bulk film upon the increase of the number of heat pulses. Therefore, Ni consumption is composed of two competition mechanisms: $\mathrm{NiSi}_{2}$ formation and $\mathrm{Ni}$ diffusion into the bulk Mo. The Si crystallization process is influenced by both mechanisms.

\section{a-Si and poly-Si thin film solar cells and characteristics}

In order to demonstrate the PRTA process I preparing the thin film poly-Si solar cell, we have fabricated thin film a-Si solar cell and tested its life time. The complete thin-film a-Si solar cell was fabricated from the joint effort of our group, i.e., Corning 1737 glass/bottom Mo (100nm)/Ni (1nm) electrode and top ITO $(80 \mathrm{~nm})$ electrode, and Dr. Q. Wang's group in NREL, i.e., PECVD n $/ 1 / \mathrm{p}^{+}$ stack at $200^{\circ} \mathrm{C}$. Figure 11 shows a typical J-V curve of a $400 \mu$ x $400 \mu$ cell, which has a conversion efficiency of $\sim 5 \%, \mathrm{~V}_{\mathrm{oc}}$ of $0.845 \mathrm{~V}, \mathrm{~J}_{\mathrm{sc}}$ of $11.3 \mathrm{~mA} / \mathrm{cm}^{2}$, and fill factor FF of $53.4 \%$. Similar results have been obtained for cells with the a-Si layer thickness of $250 \mathrm{~nm}$ to $2 \mu \mathrm{m}$. The cell was measured under AM 1.5 condition. This result is consistent with the cell completely made by NREL material, i.e., stainless steel/Ag/ $\mathrm{ZnO} / \mathrm{n}^{+} / \mathrm{i} / \mathrm{p}^{+} / \mathrm{ITO}$. Therefore, the $\mathrm{Mo} / \mathrm{Ni}$ electrode is compatible with the thinfilm a-Si and poly-Si solar cell manufacturing processes.

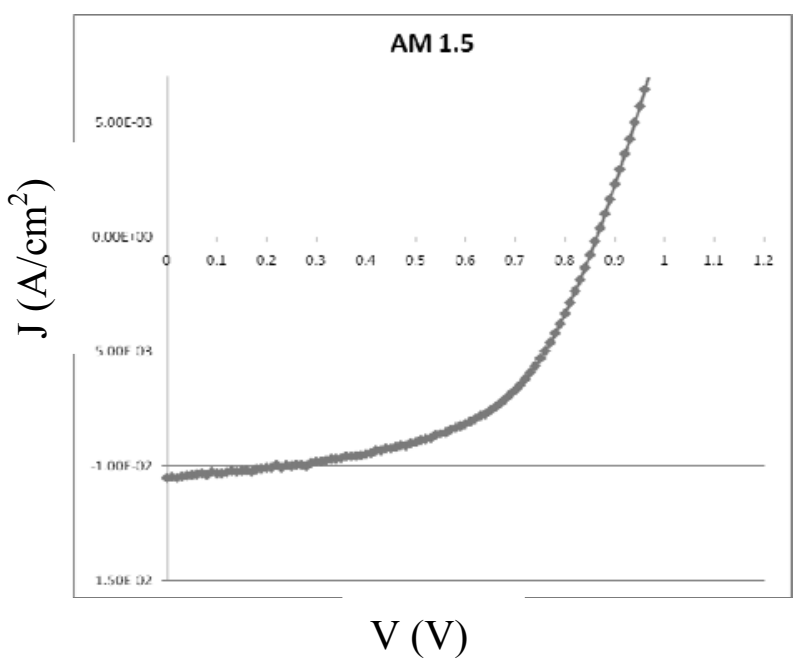

Fig. 11. J-V curve of a thin-film a-Si solar cell.

Figure 12 shows the deterioration of a thin film a-Si solar cell with solar light exposure time. The sample was not purposely cooled or heated. Typically, the reduction of the solar cell occurs in the early stage of application. This figure shows that the deterioration of the cell with the Mo/Ni bottom electrode is similar to the conventional cell with other types of bottom electrodes, i.e., a large drop of the efficiency in the first 40 hours of operation followed by slowly small drop of the efficiency and 
other parameters afterwards.

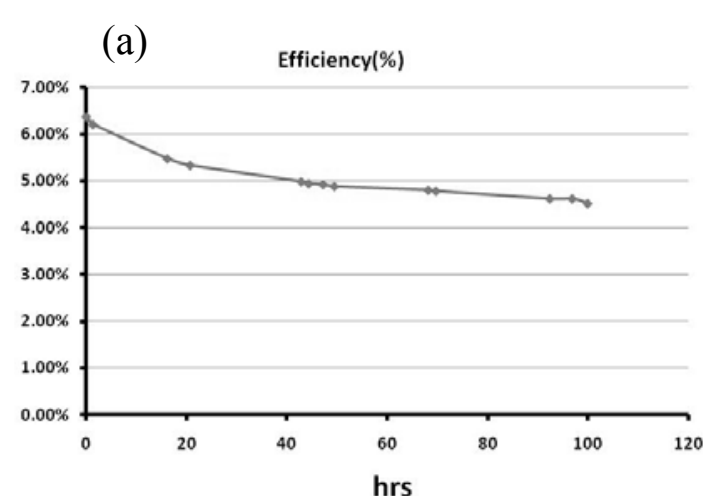

(c)

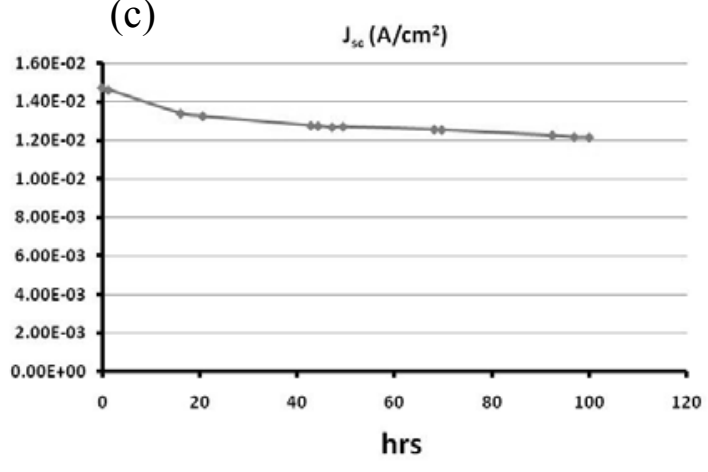

(b)

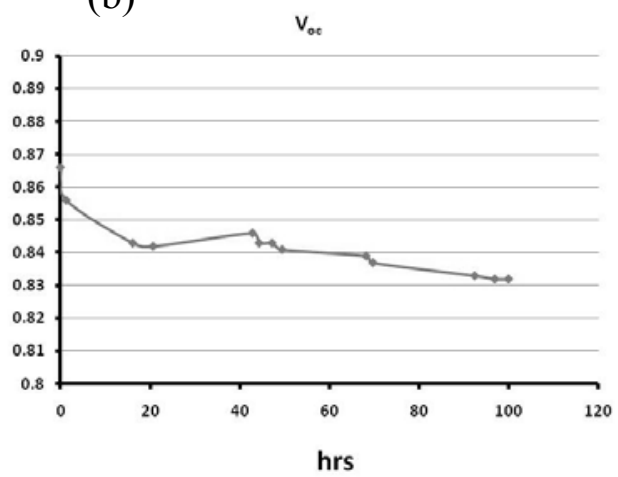

(d)

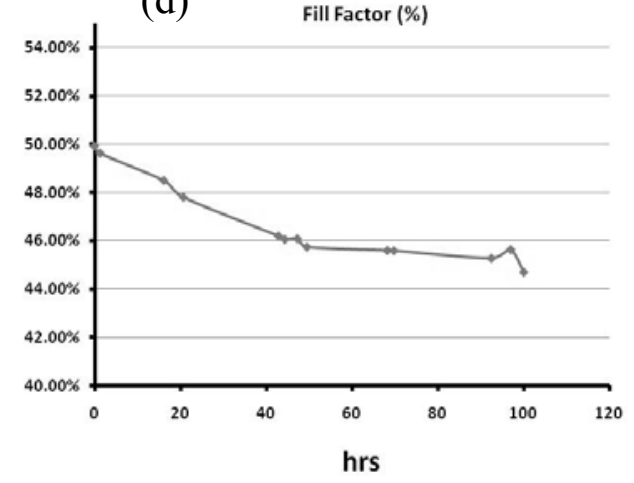

Fig. 2. 100-hr life test of an a-Si solar cell (with Mo/Ni bottom electrode) at 1.5M (a) conversion efficiency, (b) $\mathrm{V}_{\mathrm{oc}}$, (c) $\mathrm{J}_{\mathrm{sc}}$, and (d) fill factor.

Based on the above functional a-Si thin film solar cell, we have fabricated several new poly-Si pin structures on $\mathrm{Mo} / \mathrm{Ni}$ coated Corning glass using the PRTA process, i.e., from a-Si pin stack after $500^{\circ} \mathrm{C}$ dehydrogenation and 10 pulses of $1 \mathrm{sec} .850^{\circ} \mathrm{C}$ heating and $5 \mathrm{sec}$. of cooling. After the top ITO deposition and patterning, although the original a-Si pin showed typical solar cell characteristics, the poly-Si cell had poor device characteristics, e.g., Fig. 13. The poly-Si stack behaves like a resistor with low resistivity but is also sensitive to light. The same behavior was observed on poly-Si stacks with the original intrinsic a-Si layer of thickness of $300 \mathrm{~nm}$ to $2 \mu \mathrm{m}$. It is possible that excessive dopant diffusion occurred during the poly-Si formation process. Since the poly-Si cell still shows $\mathrm{V}_{\mathrm{oc}}$ and $\mathrm{J}_{\mathrm{sc}} \neq 0$, the top and bottom electrodes are not totally shorted probably due to the separation of small size of poly-Si crystals by the residue a-Si film in the intrinsic layer.

In order to demonstrate that the intrinsic a-Si part of the poly-Si film contributes to the photovoltaic characteristics, we have carried out experiments by adding a thin 30nm thick intrinsic a-Si:H film and a $30 \mathrm{~nm} \mathrm{p}^{+}$layer to a PRTA crystallized $\mathrm{n}^{+}(30 \mathrm{~nm}) / \mathrm{a}-\mathrm{Si}(2 \mu \mathrm{m})$ stack. The result shows improved solar cell characteristics, i.e., $\mathrm{V}_{\mathrm{oc}}=0.45 \mathrm{~V}$ and $\mathrm{J}_{\mathrm{sc}}=1 \mathrm{~mA} / \mathrm{cm}^{2}$. Compared with the poly-Si nip stack directly prepared from PRTA, the new cell improved $\mathrm{V}_{\mathrm{oc}}$ by 7 times but decreased $\mathrm{J}_{\mathrm{sc}}$ by 5 times. 


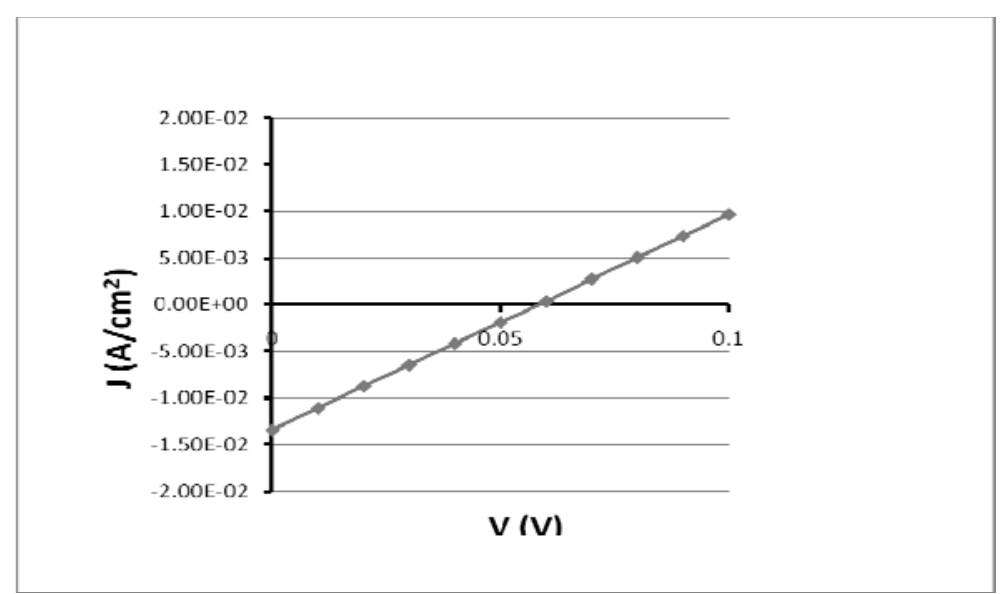

Fig. 13. J-V curve of a poly-Si solar cells under AM 1.5.

\section{CONCLUSION}

In this study, it has been demonstrated that PRTA in combination with the Ni-induced mechanism is effective in transforming the a-Si nip stack into poly-Si nip stack without deteriorating the underneath glass substrate. In principle, the poly-Si thin-film solar cell can be fabricated using this low thermal budget process. In order to achieve the high solar conversion efficiency, various process parameters, e.g., PRTA number and heating-cooling periods, and cell structures, e.g., layer thickness, electrode surface roughness, antireflective coating, need to be optimized. One of the most critical issue is to avoid the excessive diffusion of the dopant throughout the whole nip stack during the crystallization process.

\section{ACKNOWLEDGEMENT}

This research is sponsored by the DOE Golden Field Office through the DE-EE0000576 project. Authors also thank Dr. Q. Wang of NREL for technical discussions and advices.

\section{REFERENCES}

1. M. A. Green, K. Emery, Y. Hishikawa, and W. Warta, K. Emery, D. L. King, S. Igari, and W. Warta, "Solar Cell Efficiency Tables (Version 31)," Prog. Photovolt: Res. Appl. 16 61-67 (2008).

2. W. G. J. H. M. van Sark, G. W. Brandsen, M. Fleuster, M. P. Hekkert, “Analysis of the silicon market: Will thin films profit?” Energy Policy 35 3121-3125 (2007).

3. J. Jang, Chapts. 6 and 7, Polycrystalline Silicon Thin Film Transistors, Ed., Y. Kuo, Kluwer Academic Publishers, p.220-291, 2004.

4. Y. Kuo and P. M. Kozlowski, "Polycrystalline silicon formation by pulsed rapid thermal annealing of amorphous silicon,” Appl. Phys. Lett. 69 1092-1094 (1996). 
5. Q. Wang, et al., $19^{\text {th }}$ a-Si national team meeting, NREL, 5/19-20/ 2005. http://www.nrel.gov/pv/thin_film/pn_techbased_amorphous_silicon.html

6. S. Jurichich, T. J. King, K. Saraswat, and J. Mehlhaff, "Low Thermal Budget Polycrystalline Silicon-Germanium Thin-Film Transistors Fabricated by Rapid Thermal Annealing," Jpn. J. Appl. Phys. 33 L1139-L1141 (1994).

7. For example, Intevac, Inc. Model 6010

8. http://www.prnewswire.com/cgibin/stories.pl?ACCT=104\&STORY=/www/story/06-212001/0001518707\&EDATE= 